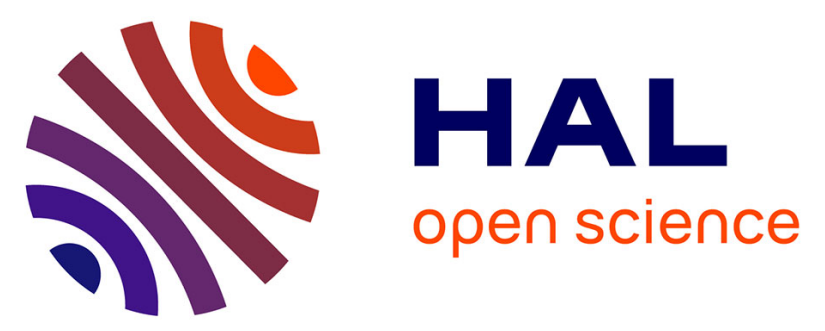

\title{
Diffusion of homologous model migrants in rubbery polystyrene: molar mass dependence and activation energy of diffusion
}

Jérémy Pinte, Catherine Joly, Patrice Dole, Alexandre Feigenbaum

\section{To cite this version:}

Jérémy Pinte, Catherine Joly, Patrice Dole, Alexandre Feigenbaum. Diffusion of homologous model migrants in rubbery polystyrene: molar mass dependence and activation energy of diffusion. Food additives \& contaminants. Part A. Chemistry, analysis, control, exposure \& risk assessment, 2010, 27 (04), pp.557-566. 10.1080/19440040903441461 . hal-00576971

\section{HAL Id: hal-00576971 \\ https://hal.science/hal-00576971}

Submitted on 16 Mar 2011

HAL is a multi-disciplinary open access archive for the deposit and dissemination of scientific research documents, whether they are published or not. The documents may come from teaching and research institutions in France or abroad, or from public or private research centers.
L'archive ouverte pluridisciplinaire HAL, est destinée au dépôt et à la diffusion de documents scientifiques de niveau recherche, publiés ou non, émanant des établissements d'enseignement et de recherche français ou étrangers, des laboratoires publics ou privés. 


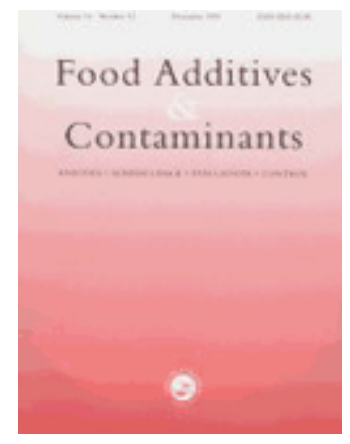

\section{DIFFUSION OF HOMOLOGOUS MODEL MIGRANTS IN RUBBERY POLYSTYRENES: MOLAR MASS DEPENDENCE AND ACTIVATION ENERGY OF DIFFUSION}

\begin{tabular}{|r|l|}
\hline Journal: & Food Additives and Contaminants \\
\hline Manuscript ID: & TFAC-2009-143.R1 \\
\hline Manuscript Type: & Original Research Paper \\
\hline Date Submitted by the \\
Author: & 21 -Oct-2009 \\
\hline Complete List of Authors: & $\begin{array}{l}\text { Joly, Catherine; UMR INRA URCA FARE; ESIEC } \\
\text { Joly, Catherine; University of Lyon 1, LRGIA- IUT }\end{array}$ \\
\hline Methods/Techniques: & Chromatographic analysis \\
\hline Additives/Contaminants: & $\begin{array}{l}\text { Packaging overall migration, Packaging plasticisers, Plasticisers, } \\
\text { Simulants }\end{array}$ \\
\hline Food Types: & \\
\hline \multicolumn{2}{|c}{} \\
\hline
\end{tabular}

\section{SCHOLARONE Manuscripts}




\section{Diffusion of homologous Model Migrants in Rubbery Polystyrene:}

2 MOLAR MASS DEPENDENCE AND ACTIVATION ENERGY OF DIFFUSION

3

4

UMR FARE (INRA-URCA), Moulin de la Housse, BP 1039, 51867 Reims Cedex 2, France

ESIEC (Ecole Supérieure d'Ingénieurs en Emballage et Conditionnement), Pôle Technologique Henri Farman, BP 1029, F-51686 Reims Cedex 2, France

Corresponding author. (Phone: +33 3269138 22, fax:+33 3269139 16)

\section{ABSTRACT:}

The published diffusion prediction models devoted to the diffusion of additives in food packaging simplify reality by having only a few parameters. Therefore, extrapolation of such models to barrier polymers, larger ranges of temperature and/or additive molecular weight $\left(\mathrm{M}_{\mathrm{W}}\right)$ are still questionable. Extra data is still required to generalize these existing prediction models. In this paper, diffusion of a specifically designed homologous set of model additives (from 236 to 1120 g.mol ${ }^{-1}$ ) was monitored in two polystyrenes at rubbery state (from 100 to $180^{\circ} \mathrm{C}$ ): syndiotactic semi-crystalline polystyrene and its amorphous equivalent. Variations of $\mathrm{D}$ and Ea with migrant $\mathrm{M}_{\mathrm{W}}$ and temperature were found to be surprisingly low. Comparison of experimental behaviour with model predictions was performed. In their actual form, none of the models is clearly able to describe all experimental data, but clues can be given, showing converging of the different approaches.

Keywords: Diffusion coefficient; FRAP; molecular weight; activation energy; polystyrene; model probes 


\section{Introduction}

2

3 To ensure consumer health, food packaging materials must be inert to packaged foodstuffs, in

4 order to avoid contamination from harmful substances which can migrate from packaging 5 materials. When dealing with plastic, regulations reinforce the concept of an Overall 6 Migration Limit (OML) with a Specific Migration Limit (SML) for potentially toxic 7 substances filed in a positive list. Petitioners for a new packaging material and control 8 authorities have to test polymeric packaging to assess their compliance for food contact (e.g. 9 US Food Law Act and EU regulation 2002/72/CE).

Migration is kinetically limited by the diffusion step within the polymer matrix, and is 11 characterized by the associated diffusion coefficient $\mathrm{D}$. The large amount of diffusion data in 12 polyolefins has made the drawing of good prediction models possible. These are useful in 13 predicting migration rate into foodstuffs or food simulants. Recently, food safety authorities 14 have allowed their use in food packaging material assessments (e.g. art. 4 in EU regulation 15 2002/72/CE).

\section{Prediction of diffusion coefficients}

18 Different approaches have been developed to model diffusion in polymeric matrixes. From

19 Piringer's work, which set up a worst case model (eq. 1) to Limm and Hollifield's model (eq. 20 2), the diffusion processes can be simplified and implemented in ready-to-use models.

$$
D^{*}=10^{4} \cdot \exp \left(A_{P}^{\prime}-\frac{C}{T}-0.003 M_{W}\left(45 \cdot M_{W}^{-1 / 3}-1\right)-\frac{10454}{T}\right)
$$




$$
D\left(T, M_{W}\right)=D_{0}^{\prime} \cdot \exp \left(\alpha \cdot M_{W}^{1 / 2}-K \frac{M_{W}^{1 / 3}}{T}\right)
$$

where $\quad \mathrm{D}$ is the predicted diffusion coefficient $\left(\mathrm{cm}^{2} \cdot \mathrm{s}^{-1}\right)$,

$\mathrm{D}^{\prime}{ }_{0}$ is the diffusion coefficient at infinite temperature $\left(\mathrm{cm}^{2} \cdot \mathrm{s}^{-1}\right)$,

$\alpha$ and $\mathrm{K}$ are tabulated polymer parameters (dimensionless),

$\mathrm{T}$ is the absolute temperature (K),

$\mathrm{M}_{\mathrm{W}}$ is the molecular weight of the diffusion species $\left(\mathrm{g} \cdot \mathrm{mol}^{-1}\right)$.

The reliability of such empirical models has been tested (Reynier et al. 1999; Helmroth et al. 2002; Rosca et Vergnaud 2006). Both models are able to describe the diffusion of additives in polyolefins, but prediction errors become significant when dealing with less mobile polymers, or when enlarging the extrapolation range to high temperatures or $\mathrm{M}_{\mathrm{WS}}$ (Feigenbaum et al. 2005; Dole et al. 2006).

With the goal of creating a more general model, Dole et al. proposed a different approach to predict $\mathrm{D}$ with additive molecular weights that try to encompass both mobile and barrier polymers (Figure 1) (Dole et al. 2006). The $\mathrm{D}=\mathrm{f}\left(\mathrm{M}_{\mathrm{W}}\right)$ correlations for a broad range of polymers were measured. They then showed that the negative slope of these $\left[\log _{10} \mathrm{D}=\mathrm{f}\left(\mathrm{M}_{\mathrm{W}}\right)\right]$ correlations decreased from high barrier polymers to lower barrier ones, while the Piringer model uses the same slope for all polymers and the Limm model integrates a weaker dependence. Consequently, as temperature directly affects polymer barrier properties (i.e. matrix mobility), Dole et al. suggested that this high slope variation leads to a variation of apparent Ea with temperature and $\mathrm{M}_{\mathrm{W}}$. The empirical models above can still predict worst case values, but the safety margins may be drastically reduced from polyolefins to other extrapolated systems.

\section{Toward a general predictive model for additive diffusion in polymers?}


1 The Dole approach provides a more complex view of diffusion: the $D=f\left(M_{W}\right)$ and $E a=f\left(M_{W}\right)$

2 slopes are functions of additive $\mathrm{M}_{\mathrm{W}}$ but first strongly depend on polymer mobility (Table 1).

3 It is worth noting that both plasticization and $\mathrm{T}$ increase allow a barrier polymer to turn into a

4 more mobile one (plasticized vs. non-plasticized PVC, dry vs. 60\%RH PA in Figure 1)

Piringer's model was built using diffusion coefficients of additives whose $\mathrm{M}_{\mathrm{W}}$ was 6 smaller than 500 g.mol ${ }^{-1}$. Dole et al. studied monitored diffusion of additives whose $\mathrm{M}_{\mathrm{W}}$ was 7 up to 807 g.mol ${ }^{-1}$ but with very few data between 430 and 807 g.mol ${ }^{-1}$. Extrapolation for high $8 \quad \mathrm{M}_{\mathrm{W}}$ additives still needs to be evaluated. In contrast, tabulated parameters in Limm's model 9 were determined by fitting with D of Irganox 1076 (531 g.mol $\left.{ }^{-1}\right)$ and Irganox 1010 (1178 10 g.mol ${ }^{-1}$ ). Therefore, Limm's model may not accurately predict the diffusion of small 11 additives.

12 When dealing with additives of increasing $\mathrm{M}_{\mathrm{W}}$, the overall size, shape, and chemical 13 functionality vary. Therefore, diffusion data of commercial additives are quite scattered. 14 However, the models mentioned above average the molecular size effect by considering only $15 \mathrm{M}_{\mathrm{W}}$. Up to now, only the Piringer model was validated experimentally against a homologous 16 series of alkanes and alcohols (Reynier et al. 2001; Reynier et al. 2001).

17

The same parallel can be drawn for the temperature range. The three models were all built for a specific temperature range. The Piringer model has to be used at a given temperature range depending on the studied polymer $\left(175^{\circ} \mathrm{C}\right.$ for $\mathrm{PET}, 70{ }^{\circ} \mathrm{C}$ maximum for PS). Limm and Hollifield fits $\alpha$ and $\mathrm{K}$ parameters between 40 and $70{ }^{\circ} \mathrm{C}$. The Dole approach describes diffusion data at $40{ }^{\circ} \mathrm{C}$ but encompasses a great range of polymer mobility. This model is therefore able to describe diffusion over an equivalent range of temperature. Reynier et al. have shown that diffusion activation by a temperature increase or plasticization fits the general relationship drawn in Figure 1 (Reynier et al. 2001). 
In order to determine the extent of $\mathrm{D}$ dependance on $\mathrm{M}_{\mathrm{W}^{-}}, \mathrm{T}$ - and polymer mobility, it is

2 still necessary to accumulate D data from homologous systems. This could then help to

3 determine proper fitting model parameters for barrier polymers and could lead to a general

4 model.

Therefore, this study was set up to follow the diffusion of a specifically designed homologous set of high $\mathrm{M}_{\mathrm{W}}$ probes (Pinte et al. 2008). These probes were chosen to be probably more accurately model commercial additives than alkanes used by Reynier et al. (Reynier et al. 2001). Moreover, they are dedicated to the use of the FRAP technique. The FRAP technique (Fluorescence Recovery After Photobleaching) is a microscopic technique used to monitor diffusion in both biological samples (Seiffert et Oppermann 2005), and material ones (Smith 1986; Tseng et al. 2000). It allows the observation of a micro-domain of the packaging material, without simulant (or food) interactions. This offers a quick determination of intrinsic apparent diffusion coefficients of model additives, especially when dealing with low mobility matrixesfrom. The chosen matrix is PS, for which little modelling validation has been obtained up to now for the following reasons:

i PS can be either totally amorphous or semi crystalline, depending on its tacticity, ii It's relatively high glass transition temperature $(\mathrm{Tg})$ facilitates measurements in the vicinity of $\mathrm{Tg}$, even at a glassy state,

iii PS displays a large rubbery plateau without any important structural change (cold crystallization, melting). As a crystalline PS, syndiotactic PS (sPS) was preferred to isotactic PS because of its higher cold-crystallization and melting temperatures. When correctly annealed, sPS shows no post-crystallization or melting over the studied range of temperatures $\left(100\right.$ to $\left.180{ }^{\circ} \mathrm{C}\right)$. 
To resume, the relationships $\mathrm{D}=\mathrm{f}\left(\mathrm{M}_{\mathrm{W}}\right)$ and $\mathrm{D}=\mathrm{f}(1 / \mathrm{T})$ are established and discussed in

2 this paper. Effects of crystallinity are also discussed. Comparison of experimental behavior

3 with model predictions is made.

4

\section{$5 \quad$ Material and methods}

\section{$6 \quad$ Material}

7 Amorphous atactic model polystyrene PS2M was obtained as a SEC (steric exclusion 8 chromatography) standard from Sigma Aldrich (Saint Quentin Fallavier, France): $9 \quad \overline{\mathrm{M}_{\mathrm{w}}}=1850000 \mathrm{~g} \cdot \mathrm{mol}^{-1}, \overline{\mathrm{M}_{\mathrm{n}}}=1760000 \mathrm{~g} \cdot \mathrm{mo}^{\mathrm{l}-1}, \overline{\mathrm{M}_{\mathrm{w}}} / \overline{\mathrm{M}_{\mathrm{n}}}=1.05$. Syndiotactic polystyrene 10 was purchased from Scientific Polymer Products (Ontario, USA): approx. $11 \overline{\mathrm{M}_{\mathrm{W}}}=300000 \mathrm{~g} \cdot \mathrm{mol}^{-1}$, density=1.05.

12 The series of fluorescent probes was synthesized as previously described (Pinte et al. 13 2008). This set of five homologous molecules, as shown in table 2 , was made by grafting a 14 fluorescent head (7-nitrobenzofurazan) onto an amino acid-like tail. This "tail" was 15 synthesized by oligomerization of the same repeating unit. Tail molecular weight was 16 increased by repeating the same 'monomer-like' unit. For more detailed synthetic procedures, 17 please refer to the above mentioned article and its Supporting Information.

\section{Methods}

20 Both polymers were characterized by differential scanning calorimetry (MDSC 2940, TA 21 Instruments). The heating rate was $10 \mathrm{~K} \cdot \mathrm{min}^{-1}$. Glass transition temperatures were determined 22 as the inflection point of heat flow from the second run, whereas melting temperature and 23 melting enthalpy were determined from the first run. For sPS, crystallinity was found to be $2470 \%$, assuming a heat of fusion of $53 \mathrm{~J}^{\mathrm{mol}}{ }^{-1}$ (Bruzaud et al. 2005). Both thermograms are 25 shown in figure 2. 
2 Films of amorphous polystyrene for FRAP experiments (PS2M) were made as described in

3 (Pinte et al. 2008) by casting from an ethyl acetate solution onto a cover slide, followed by

4 solvent evaporation under dynamic vacuum at $90{ }^{\circ} \mathrm{C}$, The cover slides were then mounted onto a

5 microscope slide by slight pressure and heating at 120_C for several seconds. SPS is non soluble in

6 the same systems as aPS. Therefore, samples were made using the following method:

i dissolution in a refluxed toluene solution containing the proper amount of the fluorescent probe,

ii casting on a hot plate $\left(100{ }^{\circ} \mathrm{C}\right)$ to allow quick evaporation of toluene and to avoid sPS precipitation,

iii removal of toluene traces at $90{ }^{\circ} \mathrm{C}$ in a dynamic vacuum oven for two days,

iv pressing a small piece of doped sPS between a glass microscope slide and a glass cover slide at $270{ }^{\circ} \mathrm{C}$.

In order to have fixed crystallinity sPS samples, sPS slides were annealed at $270{ }^{\circ} \mathrm{C}$ for 2 minutes and cooled at constant rate of $10{ }^{\circ} \mathrm{C} \cdot \mathrm{min}^{-1}$ to allow crystallization to occur.

DSC showed no cold crystallization peak when heating these samples above $\mathrm{Tg}$, up to melting point.

Fluorescent probe diffusion was monitored by confocal Fluorescence Recovery After Photobleaching (FRAP) as described elsewhere (Pinte et al. 2008). This microscopic technique has been previously used as a relevant method to collect D data in polymers (Smith 1986). FRAP creates an in situ concentration gradient in the bulk of small polymer samples. The flux of the fluorescent species then induces an intensity fluctuation over the Region of interest (ROI). From a practical point of view, FRAP experiments are conducted in three steps: (i) reading the initial intensity with low laser power, (ii) bleaching a specified area by scanning a selected region of the sample (the ROI) with very high laser power, thus 
1 photolysing the illuminated fluorescent probe, (iii) reading the recovery of the fluorescence

2 intensity over time with low laser power. As intensity is assumed to be proportional to local

3 probe concentration, D can be calculated from the fluorescence recovery kinetics. The

4 bleached ROIs were ranging from $1.5 \times 20 \mu \mathrm{m}$ for low diffusing experiments to $67 \times 61 \mu \mathrm{m}$

5 for diffusion at high temperatures.

6 The Shape ratio of the different probes used for FRAP experiment, denoting the ratio of a

7 migrant's major dimension to its minor dimension was determined from NBDNEt2 to

8 NBDNpip4. By 3D-drawing the molecules using MarvinSpace (software from ChemAxon),

9 both dimension of the molecules then the shape ratio were easily determined.

10 Experiments were set at a higher temperature than allowed on the microscope sample 11 holder. Therefore, sample slides were mounted once for reading and bleaching, then 12 demounted to be heated between two hot plates of a heating press, cooled down as quickly as 13 possible and remounted to read the fluorescence profile evolution. The last steps were 14 repeated until ROI intensity had varied enough to calculate D. Since the sample requires time 15 to reach thermal equilibrium under the press, diffusion time (i.e. time spent in the heating 16 press) was corrected to take this into account, assuming diffusion at lower temperatures to be 17 negligible.

18 To help re-localization in the sample when re-mounting under the confocal microscope, 19 thin copper grids (Oxford Instruments, Saclay, France) were immersed in the PS in the casted 20 drop of PS2M or in the molten piece of sPS. The hexagonal pattern (figure 3) provides 21 valuable information when saved coordinates failed to precisely point to the region of 22 interest. Due to the high temperatures required for the experiments, sandwiches of slides/PS 23 sample/coverslide were sealed with epoxy glue instead of nail polish. 
FRAP kinetics were processed as described elsewhere (Pinte et al. 2008). Due to quick

2 diffusion (as high temperatures were explored), bleached ROIs were enlarged to extend

3 recovery timescales. Unfortunately, bleaching was not efficient enough in the depth of the

4 sample and apparent anomalous fluorescence recovery had to be corrected. As a consequence,

5 the mathematical analysis implemented by Pinte et al. was slightly modified to eliminate this

6 unwanted diffusion from planes below and above the focal plane and to analyze fluorescence

7 recovery due to $\mathrm{x}$-axis $1 \mathrm{D}$ diffusion.

8 Several authors using the FRAP method have reported immobile fractions when

9 monitoring diffusion in complex systems (Miura 2004, Karboviak et al. 2006).

10 Consequentially, equilibrium intensity in the bleached area may not be the same as in the

11 initial one. The ratio of the final intensity to the initial one represents the percentage of 12 mobile probes. The difference between this value and $100 \%$ then gives the amount of non 13 mobile probes. Our diffusion experiments in syndiotactic polystyrene were therefore first 14 conducted for a much longer time (6 months) than in the usual procedure in order to estimate 15 the equilibrium intensity.

\section{Results and discussion}

18 PS samples containing the probes $\left(5 \times 10^{-10}\right.$ mol. $\left.\mathrm{mg}^{-1}\right)$ were obtained. All probes were 19 correctly dispersed in the polymer matrixes, notwithstanding whether these were amorphous 20 or crystalline. However, some patterns were observed in sPS, revealing the partial exclusion 21 of fluorescent probes from more crystalline regions. This did not disturb FRAP experiments 22 and diffusion of the different items of the homologous set was monitored in PS2M and in sPS 23 for different temperatures ranging from 120 to $180{ }^{\circ} \mathrm{C}$. 
Literature on the FRAP technique mentions that in the case of complex polymer systems, fluorescence recovery may not be total which is to be taken into account in the D calculation. For example, Equilibrium intensity is lower, denoting non mobile probes. This is supposed to be the case in semi-crystalline polymers where some of the probes could be entrapped and not available for diffusion. This was checked in this study but no immobile fraction was observed, even if some patterns could be observed in sPS samples (figure 3sPS). Diffusion was found to be very similar in PS2M and in sPS. Equilibrium intensities were not different and close to the initial ones (less than a $10 \%$ decrease). Crystallinity did not induce a bigger change in mobile/non mobile probe ratios. Therefore, initial intensities were used as equilibrium intensities.

Diffusion coefficients were measured for the five homologous probes, whose $\mathrm{M}_{\mathrm{W}}$ ranged from 236 to 1120 g.mol ${ }^{-1}$, in both amorphous and semi-crystalline PS, with an experimental temperature increases from $100{ }^{\circ} \mathrm{C}$ to $180{ }^{\circ} \mathrm{C}$. Those for PS2M are reported in table 3.

\section{$\left[\log _{10} D=f\left(M_{W}\right)\right]$ correlations}

Diffusion coefficients as a function of $\mathrm{M}_{\mathrm{W}}$ for different temperatures are plotted on Figure 4. The total decrease of $\log _{10} \mathrm{D}$ with $\mathrm{M}_{\mathrm{W}}$ for different temperatures is shown in table 3 . Increasing $\mathrm{M}_{\mathrm{W}}$ from 236 to 1120 g.mol ${ }^{-1}$ lead to a decrease of about two units of $\log _{10} \mathrm{D}$ for all the tested temperatures. Indeed, as shown in figure 4, an arbitrary line can fit all data at rubbery state, by only vertical shifts as lines are parallel. As reported in Table 3, the slope can be considered as almost constant, when not taking into account data at $100^{\circ} \mathrm{C}$. The slope seemed smaller at $100^{\circ} \mathrm{C}$, when PS2M is at its DSC glass transition temperature. 
The constancy of the $\log _{10} \mathrm{D}=\mathrm{f}\left(\mathrm{M}_{\mathrm{W}}\right)$ slope correlations relates the PS2M data to the

2 Piringer model, where influence of $\mathrm{M}_{\mathrm{W}}$ and $\mathrm{T}$ on $\mathrm{D}$ are independent. The $\mathrm{D}$ decrease is quite

3 small (roughly from 1 to 2 orders of magnitude) for an 890 g. mol ${ }^{-1}$ increase of the migrant

4 molecular weight. For example, Reynier et al. reported a 4orderofmagnitude decrease for

5 diffusion in polyolefins over the same range but for lower $\mathrm{M}_{\mathrm{W}}$ (from 156 to 807 g.mol ${ }^{-1}$ )

6 (Reynier et al. 2001). But, the first molecule of the homologous series used in this study has

7 a higher $\mathrm{M}_{\mathrm{W}}$ compared to Reynier et al.'s one which was made for a migrant molecular

8 weight between Npip2 and Npip3. As reported by Dole et al., the sharp decrease observed

9 forD mainly occurs for rather low $\mathrm{M}_{\mathrm{W}}$ that is to say between gases and small additives $\left(\mathrm{M}_{\mathrm{W}}\right.$

10 less than 200 g. $\mathrm{mol}^{-1}$ ). For higher molecular weight additives, extrapolation of such $\mathrm{D}=$ $11 \mathrm{f}(\mathrm{Mw})$ curves could leads, in the present study, to a flatter slope of $\mathrm{D}=\mathrm{f}\left(\mathrm{M}_{\mathrm{W}}\right)$ (Dole et al. 12 2006).

13 Migrant shape (steric hindrance) is known to be a limiting parameter for diffusion, 14 whereas increasing migrant degrees of freedom counterbalances this by increasing diffusion 15 (Al-Malaika et al. 1991). Reynier has reported a high decrease as predicted by the Piringer 16 model when taking into account homologous series of both alkanes and alcohols as well as 17 commercial additives for higher $\mathrm{M}_{\mathrm{W}}$ (Reynier et al. 2001). They observed that for high $\mathrm{M}_{\mathrm{W}}$ 18 migrants, increasing the degrees of freedom of the arms lead to a relative increase of D 19 (trilaurine and tripalmitine with long alkyl arms compared to Irgafos 168 and Irganox 1330, 20 with highly hindered arms). In fact, in our study, D decrease with migrant Mw is rather low 21 as reported above. This can be explained by the model additives series which are not shape22 homologous over the whole range of $\mathrm{M}_{\mathrm{W}}$ (as initially expected). Although they all have a 23 worm-like shape (shape ratio $<1$ as shown in figure 5), and due to the repet unit (table 3), this 24 ratio decreases along the series: $\mathrm{NBDNet}_{2}$ has a more spherical shape than NBDNpip . 25 Moreover, when jumping from NBDNet 2 to NBDNpip $_{1}$, no extra degree of freedom is added, 
1 in contrast to the change from $\mathrm{NBDNpip}_{\mathrm{n}}$ to $\mathrm{NBDNpip}_{\mathrm{n}+1}$. where the migrant linearity is

2 improved. This provides extra degrees of freedom when increasing migrant $\mathrm{M}_{\mathrm{W}}$ and thus, the

3 influence of shape through $\mathrm{M}_{\mathrm{W}}$ on $\mathrm{D}$ seems to be minimized.

4 The Piringer model implies a much higher dependence of $\mathrm{D}$ on $\mathrm{M}_{\mathrm{W}}$ (between $\mathrm{NBDNet}_{2}$ 5 and NBDNpip $4, \triangle \log _{10} \mathrm{D}=6.75$ instead of about 2 in this study). Extrapolation of the Limm 6 model and the Dole approach to higher temperatures predicts variations closer to those 7 observed in this study (respective predicted decrease $\triangle \log _{10} \mathrm{D}$ of 2.75 and 3). D values have 8 been reported to be less dependent on $\mathrm{M}_{\mathrm{W}}$ in rubbery polymers than in more barrier ones 9 (Dole et al. 2006). But the flatter slope, (figure 4), at $100{ }^{\circ} \mathrm{C}$ gives the opposite indication as 10 predicted by Dole et al.

\section{$D=f(1 / T)$ correlations}

13 In consistency with any migration model, D was found to increase when increasing 14 temperature as shown in figure 6. The different $\mathrm{D}$ values between $120^{\circ} \mathrm{C}$ and $180{ }^{\circ} \mathrm{C}$ ranged 15 from 3.2 to $3.9 \log _{10} \mathrm{D}$ units (table 3 ).

16 Close to glass transition, D variations are emphasized. Although requiring further 17 confirmation, the higher the $\mathrm{M}_{\mathrm{W}}$, the stronger the dependence with $\mathrm{T}$. For $\mathrm{NBDNet}_{2}$ to $18 \mathrm{NBDNpip}_{3}$, the D jump temperature is between 100 and $120^{\circ} \mathrm{C}$ whereas for $\mathrm{NBDNpip}_{4}$, it 19 occurs at a higher temperature (the jump is related to the $D$ data which leave the $D=f(M w)$ 20 line observed at high temperature). The Tg jump seems to be a function of $\mathrm{M}_{\mathrm{W}}$, as it is of 21 frequencies or heating speed in thermo-mechanical analysis (Sauerbrunn et al. 2003). 22 Activation energies (Ea) are calculated from the Arrhenius law as usually describes by others 23 authors (Hayashi et al.1994, Roe et al.1998). Ea is then proportional to the slope of the curves $24 \log \mathrm{D}=\mathrm{f}(1 / \mathrm{T})$ and determine from the least squares approach. For homogeneity, activation 
1 energies were calculated between 120 and $180{ }^{\circ} \mathrm{C}$, assuming they are constant over this range

2 of temperature.

3 Ea are between 140 and $180{ }^{\circ} \mathrm{C}$ slightly increased with molecular weight (table 4),

4 whereas between 120 and $180{ }^{\circ} \mathrm{C}$, it could be considered as constant, considering the data

5 scattering . Results on a reduced range limit comparison with the Piringer model, which takes

6 a constant Ea into account, and make the PS2M data closer to the Limm and Hollifield model

7 (respective increase of Ea from $\mathrm{Net}_{2}$ to $\mathrm{Npip}_{4}$ is $1.5 \mathrm{vs} 1.7$ ). The effect of $\mathrm{M}_{\mathrm{W}}$ seems to prevail

8 over the shape factor ratio, in contrast to diffusion coefficients. This odd behavior, however,

9 makes one relationship clear: the weaker the dependence of the $D=f\left(M_{W}\right)$ slope with

10 temperature, the smaller Ea variations.

11 Increasing linearity for higher $\mathrm{M}_{\mathrm{W}}$ leads to a weaker shape factor influence and 12 therefore decreasing dependence of Ea with $\mathrm{M}_{\mathrm{W}}$.

14 Ea were then compared to data in rubbery PS and LDPE. Hall et al. studied the diffusion 15 of lophine in rubbery PS between 100 and $145^{\circ} \mathrm{C}$. (Hall et al. 1999). From their data, the 16 calculated Ea $\left(272 \mathrm{~kJ} \mathrm{~mol}^{-1}\right)$ is one and a half times larger than Hall et al.'s equivalent Ea $17\left(\mathrm{M}_{\mathrm{W}}\right.$ of lophine is between that of $\mathrm{NBDNet}_{2}$ and $\left.\mathrm{NBDNpip}_{1}\right)$. This difference may lie in the 18 different shape and degree of freedom. As previously mentioned, the homologous set is worm 19 shaped with a propyl spacer between rigid cores providing degrees of freedom, whereas 20 lophine is more spherical with three short and rigid phenyl arms. This difference in Eas is 21 logical because the Ea represents the energy required to open a sufficient hole between 22 polymer chains for the migrant to diffuse: thus, a greater probe diameter means a higher Ea 23 (Al-Malaika et al. 1991; Reynier et al. 2001). However, these reported Eas are very high 24 compared to those calculated by Al-Malaika et al. (Al-Malaika et al. 1991) for homologous 25 linear 2-hydroxy benzophenones in LDPE (between 69 and $86 \mathrm{~kJ}^{\mathrm{mol}}{ }^{-1}$ from 5 to $100{ }^{\circ} \mathrm{C}$ ). 
1 This could be explain by the mobility of the matrix: the temperature gap to the $\mathrm{Tg}$ is far

2 bigger in Al-Malaika's experiment (for LDPE: T-Tg $150{ }^{\circ} \mathrm{C}$ ) than in ours $(0<\mathrm{T}-\mathrm{Tg}<80$

$\left.3{ }^{\circ} \mathrm{C}\right)$ or in Hall's $\left(0<\mathrm{T}-\mathrm{Tg}<45^{\circ} \mathrm{C}\right)$. This corroborates the suggestion of Dole et al. (Dole et

4 al. 2006) that Ea may decrease with increasing temperature, but over a larger range and

5 farther from the $\mathrm{Tg}$ than studied here.

6

7

8 Crystallinity is reported to decrease D by hampering migrant diffusion as described by

9 Hedenqvist et al. (Hedenqvist et al. 1996). Some authors even describe an exponential relationship between D and cristallinity (Klopffer and Flaconneche 2001).

Hedenqvist et al. report a five-fold reduction of D in linear PE and a two-fold one in branched PE when increasing crystallinity by 50\% (Hedenqvist et al. 1996). The same observation was made by Chiang et al. when comparing quenched pseudo amorphous sPS with isothermally crystallized sPS (Chiang et al. 2002). Such reductions are of the same magnitude of what was found in our system (Figure 7). Nevertheless, larger Ds in sPS than in PS2M at low temperature are odd. (from Figure 7 and other results not shown). In addition, no increasing difference between $\mathrm{D}_{\text {amorphous }}$ and $\mathrm{D}_{\text {crystalline with the additive }} \mathrm{M}_{\mathrm{W}}$ was found, in contrast to what Hedenqvist et al. reported. The torturous diffusion path in sPS might be counterbalanced by the increase of free volume due to increased tacticity and $\mathrm{Tg}$ heights. Highly tactic polymers have been reported to have higher free volume than atactic ones due to special chain conformation (Dammert et al. 1999; Soldera et Grohens 2002). When getting close enough to $\mathrm{Tg}$, tortuosity effect may become less important than free volume size and chain mobility. 


\section{Conclusions}

2 Diffusion in two different PS, one amorphous and one semi-crystalline, was monitored at the

3 rubbery state for five homologous probes, offering a $\mathrm{M}_{\mathrm{W}}$ range of almost $900 \mathrm{~g} \cdot \mathrm{mol}^{-1}$.

4 Diffusion was found to be less dependent on temperature or migrant molecular weight than

5 calculated from prediction models.. However, D decrease for $\mathrm{M}_{\mathrm{W}}$ range was found close to

6 the Limm model. This low dependence might be explained by the higher $\mathrm{M}_{\mathrm{W}}$ of the first

7 molecule of the model migrant series. Another hypothesis may be offered to explain the low

8 correlation between $\mathrm{D}$ and $\mathrm{M}_{\mathrm{W}}$. Even if the probes are chemically homologous, they are

9 unfortunately not ideally homologous; their shape factor varies along the series from 10 relatively square to worm-like. This variation may counteract the decrease of $\mathrm{D}$ as $\mathrm{M}_{\mathrm{W}}$ gets 11 higher. Bearing this fact in mind, none of the models can be excluded, based on the study's 12 data. Moreover, all the three models can partially explain the observed effects of $\mathrm{M}_{\mathrm{W}}$ and $\mathrm{T}$ 13 on $\mathrm{D}$.

14 Whatever hypothesis is taken into account, the following general relationship is 15 accurate: when $\mathrm{D}$ is not strongly affected by $\mathrm{Mw}$ or $\mathrm{T}$, neither is Ea. Further experiments are 16 required to develop a general model for: (i) a more shape-homologous series of designed 17 migrants, and (ii) diffusion in glassy matrices, where very little data are still available because 18 of very long diffusion time The Frap technique could help to acquire information about that 19 issue. 


\section{References}

2

3

4 5 6

Al-Malaika, S., Goonetileka, M.D.R.J., Scott, G. (1991) Migration of 4-substituted 2-hydroxy benzophenones in low density polyethylene: Part I-Diffusion characteristics. Polymer Degradation and Stability 32(2), pp 231-247.

Bruzaud,S., Grohens Y., Ilinca S., Carpentier J.F.(2005). Syndiotactic

Polystyrene/Organoclay Nanocomposites: Synthesis via In Situ Coordination-Insertion

Polymerization and Preliminary Characterization. Macromolecular Materials and Engineering 290(11), pp1106-1114.

Chiang, I. J., Chau C. C., Sanboh L. (2002). The mass transport of ethyl acetate in syndiotactic polystyrene. Polymer Engineering \& Science 42(4), pp724-732.

Dammert, R. M., Maunu, S. L., Maurer, F.H. J., Neelov, I.M., Niemela, S., Sundholm, F., Wastlund, C.(1999). "Free Volume and Tacticity in Polystyrenes." Macromolecules 32(6), pp1930-1938.

Dole, P., Feigenbaum A.E., Dole, P., De La Cruz, C., Pastorelli, S., Paseiro, P., Hankemeier, T., Voulzatis, Y., Aucejo, S., Saillard, P., Papaspyrides, C. (2006). Typical diffusion behaviour in packaging polymers: application to functional barriers. Food Additives \& Contaminants 23(2), pp 202-211.

Feigenbaum, A., P. Dole, Aucejo, S., Dainelli, D., Garcia, C., De La Cruz, Hankemeier, T., Ngono, Y., Papaspyrides, C. D., Paseiro, P., Pastorelli, S., Pavlidou, S., Pennarun, P. Y., Saillard, P., Vidal, L., Vitrac, O.Voulzatis, Y. (2005). Functional barriers: Properties and evaluation. Food Additives \& Contaminants 22(10), pp 956-967.

Hall, D. B., Hamilton K. E., Miller, R. D.,Torkelson, J.M. (1999). Translational and Rotational Diffusion of Probe Molecules in Polymer Films near Tg: Effect of Hydrogen Bonding. Macromolecules 32(24), pp 8052-8058.

Hayashi H, Sakai H., Matsuzawa S. (1994). Diffusion of methyesters of higher fatty acid in polypropylene. Journal of applied polymer science. 51, pp2165-2173. 
2 Hedenqvist, M., Angelstok A. (1996). Diffusion of small-molecule penetrants in 3 polyethylene: free volume and morphology. Polymer 37(14), pp2887-2902.

4

5 Helmroth, E., Rijk R., , Dekker, M., Jongen, W. (2002). Predictive modelling of migration 6 from packaging materials into food products for regulatory purposes. Trends in Food Science $7 \quad \&$ Technology 13(3), pp102-109.

9 Karboviak, T., Hervet H., (2006). Effect of plasticisers (water and glycerol) on the diffusion 10 of a small molecule in Iota-carrageenan biopolymer films for edible coating application. 11 Biomacromolecules 7(6), pp 2011-2019

12 Klopffer, M. H. and B. Flaconneche (2001). Transport Properdines of Gases in Polymers: 13 Bibliographic Review. Oil \& Gas Science and Technology 56(3), pp 223-244. 14

Miura, K. (2004). What do FRAP curves tell us ?. EAMNET practical course, Heidelberg, 17

Pinte, J., Joly C., , Plé, K., Dole, P., Feigenbaum, A. (2008). Proposal of a Set of Model

Polymer Additives Designed for Confocal FRAP Diffusion Experiments. Journal of Agricultural and Food Chemistry 56(21), pp 10003-10011.

Reynier, A., Dole, P., Feigenbaum, A. (1999). Prediction of worst case migration: presentation of a rigorous methodology. Food Additives and Contaminants 16, pp137-152.

Reynier, A., P. Dole, et al. (2001). "Additive diffusion coefficients in polyolefins. II. Effect of 26 swelling and temperature on the $D=f(M)$ correlation." Journal of Applied Polymer Science 82(10), pp 2434-2443.

Reynier, A., Dole P., Humbel S., Feigenbaum A., (2001). Diffusion Coefficients of Additives in Polymers. I. Correlation with Geometric Parameters. Journal of Applied Polymer Science 82(10), pp 2422-2433.

33 Roe R.J., Bair H., Gieniewsky C. (1974). Solubility and diffusion coefficient of antioxydants in polyethylene. Journal of polymer science, 18, pp 843-856. 
2 Rosca, I. D. and Vergnaud J. M. (2006). Approach for a testing system to evaluate food safety 3 with polymer packages. Polymer Testing 25(4), pp 532-543.

4

5 Sauerbrunn, S., Riesen R., (2003). Glass transition by DSC, TMA and DMA. NATAS Annual 6 Conference on Thermal Analysis and Applications, Albuquerque, NATAS. 7

8 Seiffert, S. and W. Oppermann (2005). Systematic evaluation of FRAP experiments 9 performed in a confocal laser scanning microscope. Journal of Microscopy 220(1): 20-30. 10

11 Smith, B. A. (1986). Photochemical Methods for Measuring Polymer Diffusion. 12 Photophysical and photochemical Tools in Polymer Science. M. A. Winnik, D. Reidel 13 Publishing Company, pp 397-406. 14 15 Soldera, A. and Y. Grohens (2002). Molecular modeling of the glass transition of 16 stereoregular PMMAs. Polymer-Plastics Technology and Engineering 41(3), pp561 - 571. 17

18 Tseng, K. C., Turro N. J., , Durning, C. J. (2000). Tracer diffusion in thin polystyrene films. 19 Polymer 41(12), pp 4751-4755. 
1 Table 1. Factors influencing diffusion coefficients and activation energies according to the three models

2

\begin{tabular}{|l|lcc|lll|}
\hline Model & \multicolumn{3}{|c|}{ D influencing factors } & \multicolumn{3}{|c|}{ Ea influencing factors } \\
\hline Piringer's model & $\mathbf{M}_{\mathbf{W}}$ & $\mathrm{T}$ & polymer & polymer & \\
\hline $\begin{array}{l}\text { Limm and } \\
\text { Hollifield's model }\end{array}$ & $\mathbf{M}_{\mathrm{W}}$ & $\mathrm{T}$ & polymer & polymer & $\mathrm{M}_{\mathrm{W}}$ & \\
\hline Dole's model & polymer & $\mathrm{M}_{\mathrm{W}}$ & $T$ & $\mathbf{M}_{\mathbf{W}}$ & polymer & $T$ \\
\hline
\end{tabular}


Table 2. Characteristics and structures of the homologous fluorescent set of model additives.

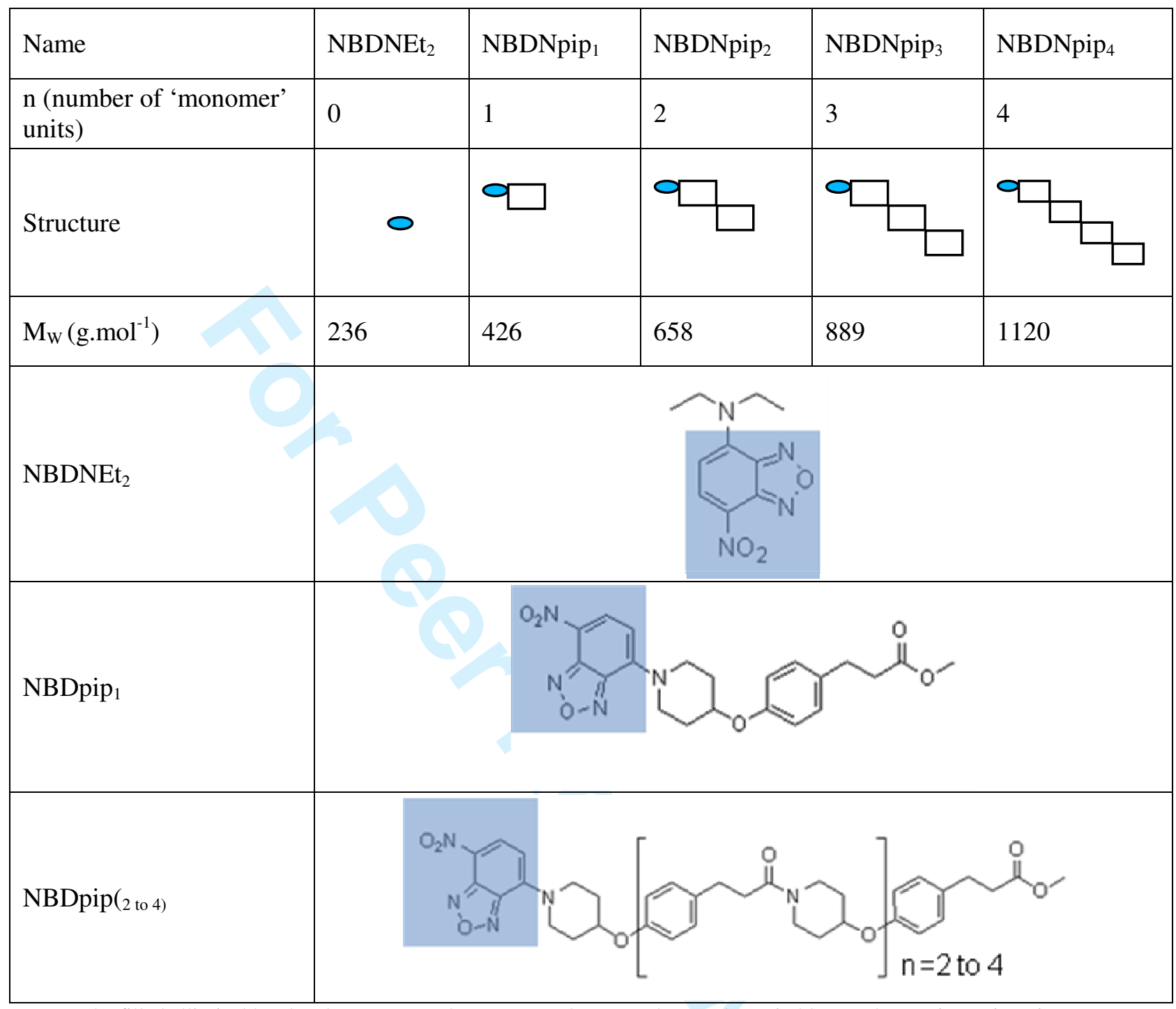


Table 3. Diffusion coefficients measured in amorphous polystyrene (PS2M) at various temperatures (D) are in $\left.10^{-12} \mathrm{~cm}^{2} \cdot \mathrm{s}^{-1}\right)$. Probes legend are given in table 2.

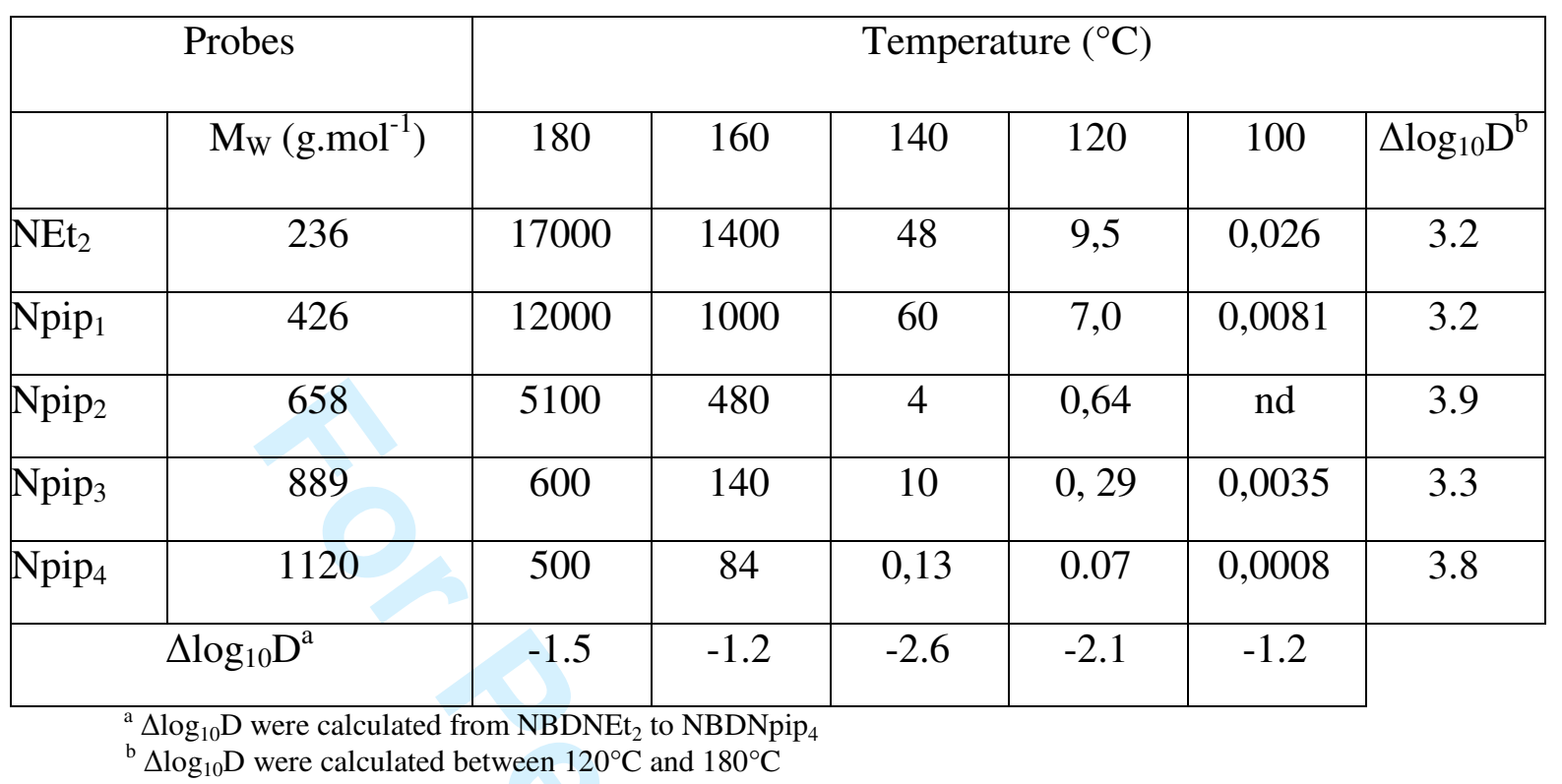


1 Table 4. Calculated activation energies (Ea) for the model additives in actactic polystyrene (PS2M). 2 Arrhenius plot of PS2M diffusion coefficients.

\begin{tabular}{|c|c|c|c|}
\hline \multirow{2}{*}{ Model additive } & \multirow{2}{*}{$\mathrm{M}_{\mathrm{W}}\left(\mathrm{g} \cdot \mathrm{mol}^{-1}\right)$} & \multicolumn{2}{|c|}{$\mathrm{Ea}\left(\mathrm{kJ} \cdot \mathrm{mol}^{-1}\right)$} \\
& 236 & 187 & 170 \\
\hline $\mathrm{Net}_{2}$ & between 120 and $180^{\circ} \mathrm{C}$ & between 140 and $180{ }^{\circ} \mathrm{C}$ \\
\hline $\mathrm{Npip}_{1}$ & 436 & 189 & 179 \\
\hline Npip $_{2}$ & 658 & 219 & 237 \\
\hline Npip $_{3}$ & 889 & 188 & 212 \\
\hline Npip $_{4}$ & 1120 & 239 & 249 \\
\hline
\end{tabular}

Ea were calculated assuming a Arrhenian behavior and a constant Ea between 120 and $180{ }^{\circ} \mathrm{C}$. 
Figure captions

4 Figure 1. Diffusive behaviour of different migrants in polymers at $40^{\circ} \mathrm{C}$, redrawn from 5 Dole et al.'s data (Dole et al. 2006).

6 Circles refer to diffusion in mobile polymers, such as LLDPE, LDPE, plasticized PVC, 7 plasticized PP), triangles show D for barrier polymers (dry PA, dry EVOH, unplasticized 8 PVC, PET, PMMA, PS), and squares refer to intermediate polymers (PA at 60\%RH, PP). 9 Diffusion was carried out at $40^{\circ} \mathrm{C}$. The arrow indicates an increasing matrix mobility, 10 embodied by the system glass transition temperature.

Figure 2. Thermal characterization of virgin PS2M (acatic polystyrene) and sPS

13 (semicrystalline syndiotactic polystyrene sPS)

Figure 3. syndioctactic polystyrene (sPS sample), showing non homogeneously dispersed 16 Npip2 probes (left), and homogeneous dispersion in amorphous polystyrene PS2M

Figure 4. Diffusion coefficients in PS2M as a function of $M_{W}$ for different temperatures.

Plain lines have the same slope, they are vertically shifted to best describe $D=f\left(M_{W}\right)$ for each temperature. The dotted line $\left(\mathrm{T}=100^{\circ} \mathrm{C}\right)$ has a different slope.

Figure 5. Shape ratio of the different probes used for FRAP experiment, from NBDNEt $_{2}$ to NBDNpip4.

26 The dimension ratio, which is equal to the largest cross section from head to tail, was 27 estimated by drawing the molecules in MarvinSpace (ChemAxon).

Figure 6. Arrhenius plot of PS2M diffusion coefficients. 
1 Lines are drawn only as guides. The dotted line (Npip4), however, has a lower slope than 2 other plain lines.

3

4 Figure 7. Comparison of the diffusion of two probes in amorphous or semi crystalline 5 polystyrenes. 


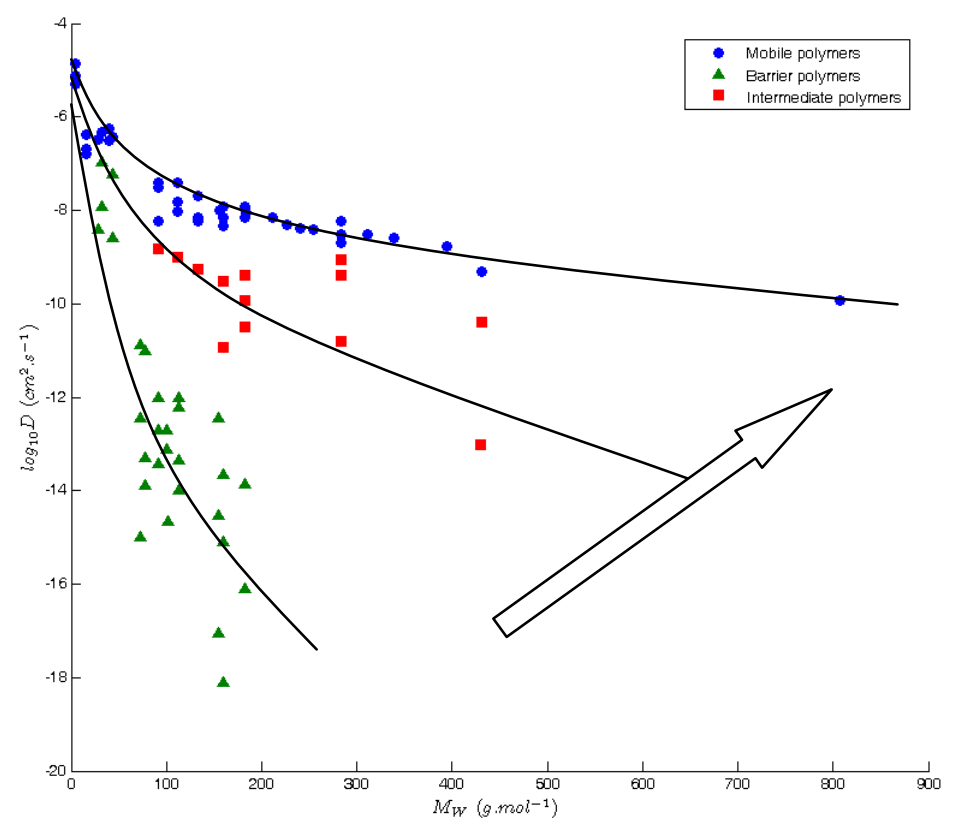

Figure 1. Diffusive behaviour of different migrants in polymers at $40^{\circ} \mathrm{C}$, redrawn from Dole et al.'s data (Dole et al. 2006).

Circles refer to diffusion in mobile polymers, such as LLDPE, LDPE, plasticized PVC, plasticized PP), triangles show D for barrier polymers (dry PA, dry EVOH, unplasticized PVC, PET, PMMA, PS), and squares refer to intermediate polymers (PA at 60\%RH, PP). Diffusion was carried out at $40^{\circ} \mathrm{C}$. The arrow indicates an increasing matrix mobility, embodied by the system glass transition temperature. 


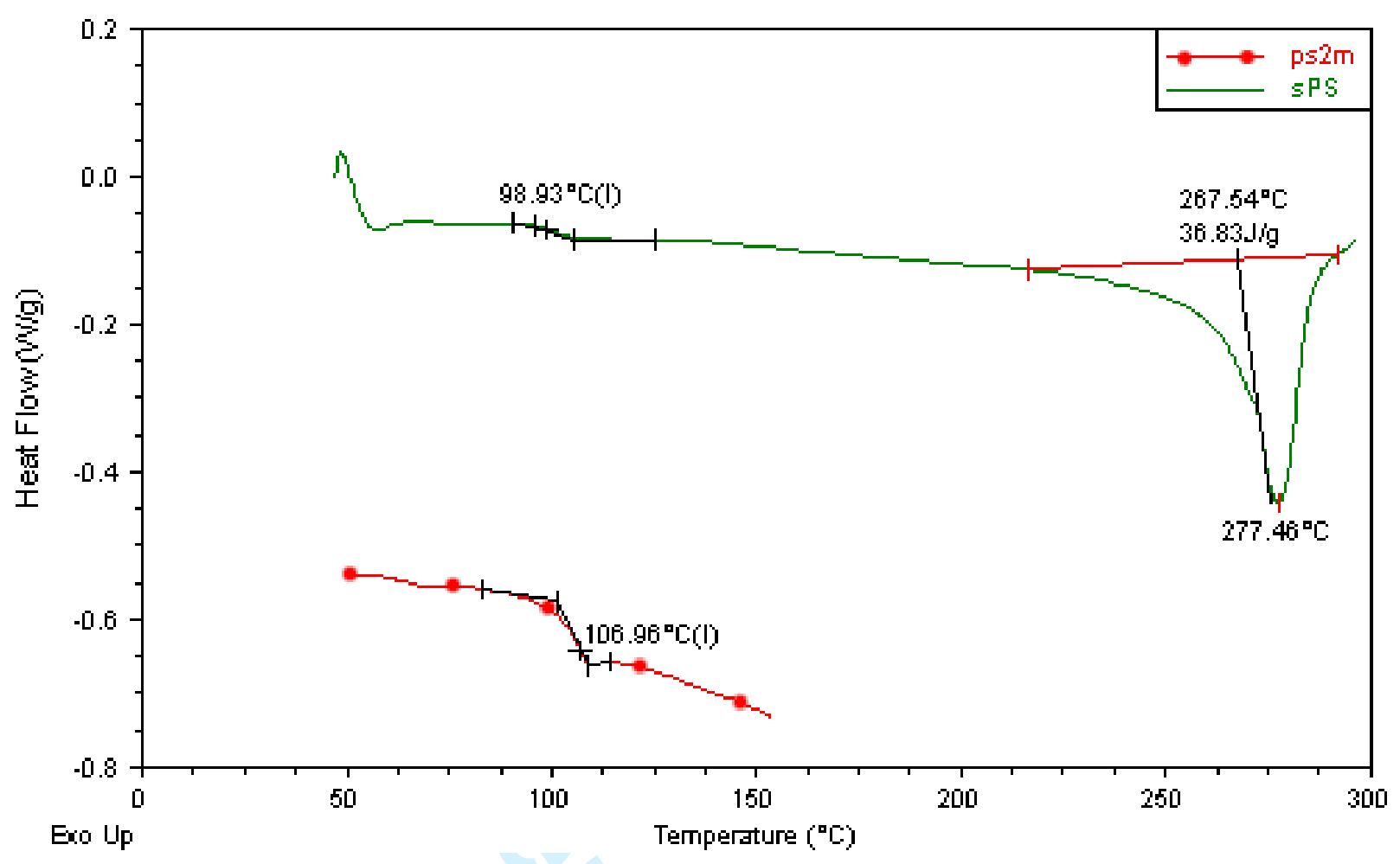

Figure 2. Thermal characterization of virgin amorphous polystyrene (PS2M) and semi ccristaline polystyrene (sPS) 

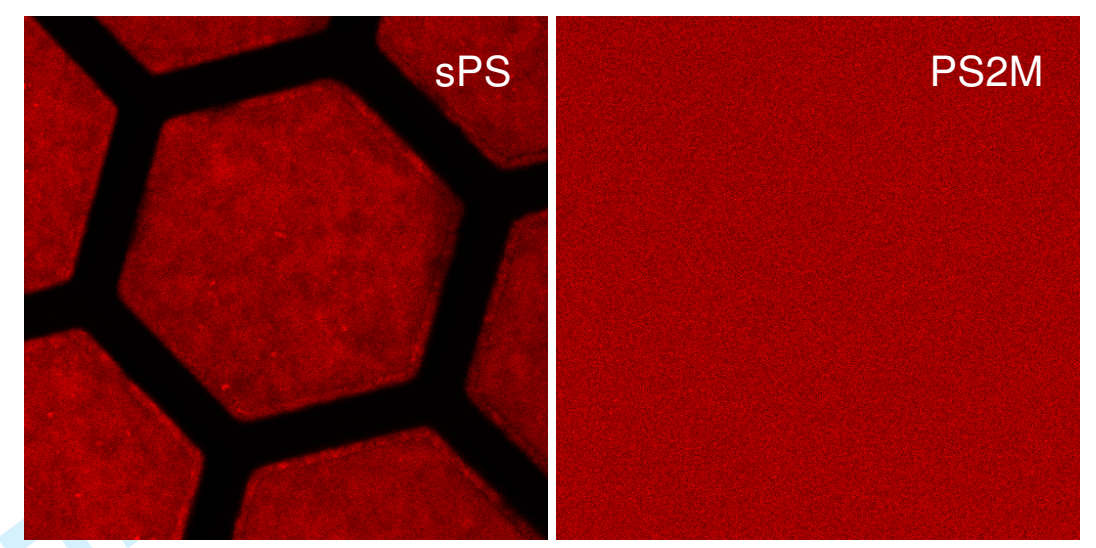

1 Figure 3. Semi-cristallilne polystyrene (sPS) sample, showing non homogeneously dispersed Npip2 probes 2 (left), and homogeneous dispersion in amorphous polystyrene (PS2M) (right). Zoom: 1.9, picture size: $3125 \times 125 \mu \mathrm{m}$. The black pattern of the copper hexagonal grid can be seen immersed in the sPS sample. 


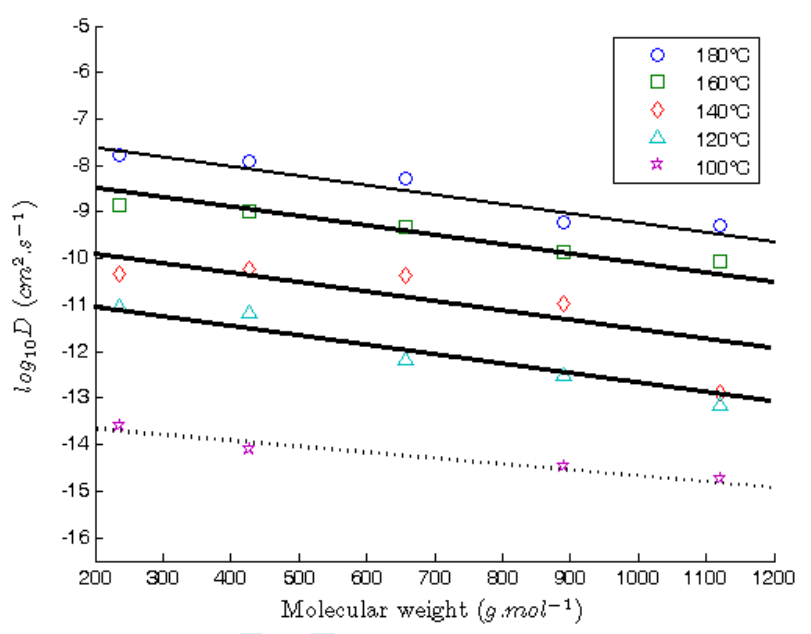

Figure 4. Diffusion coefficients in amorphous polystyrene (PS2M) as a function of probes $M_{W}$ for different 4 temperatures.

5 Plain lines have the same slope, they are vertically shifted to best describe $\mathrm{D}=\mathrm{f}\left(\mathrm{M}_{\mathrm{W}}\right)$ for each temperature. The dotted line $6 \quad\left(\mathrm{~T}=100^{\circ} \mathrm{C}\right)$ has a different slope. 
4

5

6

7 Figure 5. Shape ratio of the different probes used for FRAP experiment, from NBDNEt to $_{2}$ NBDNpip $_{4}$ 'see 8 tables 2 for probe chemical structures)

9 The dimension ratio, which is equal to the largest cross section from head to tail, was estimated by drawing the molecules in 10 MarvinSpace (ChemAxon).

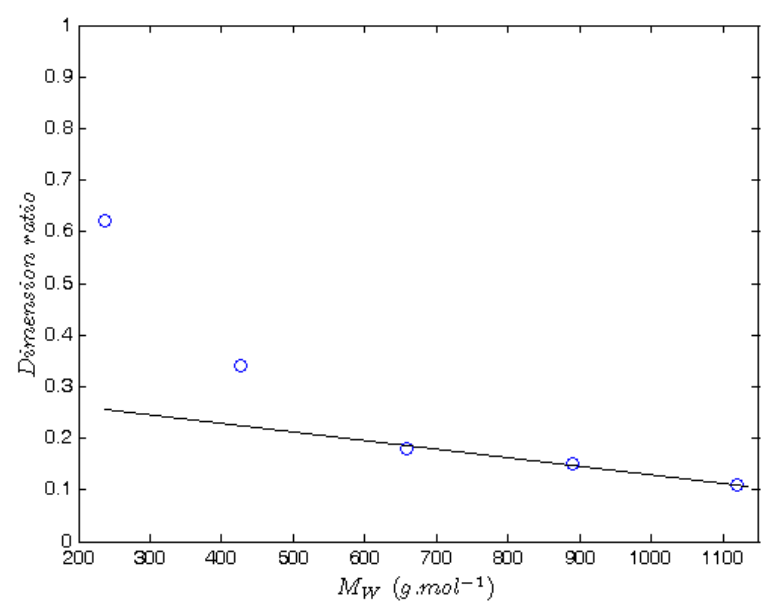


1 2 3

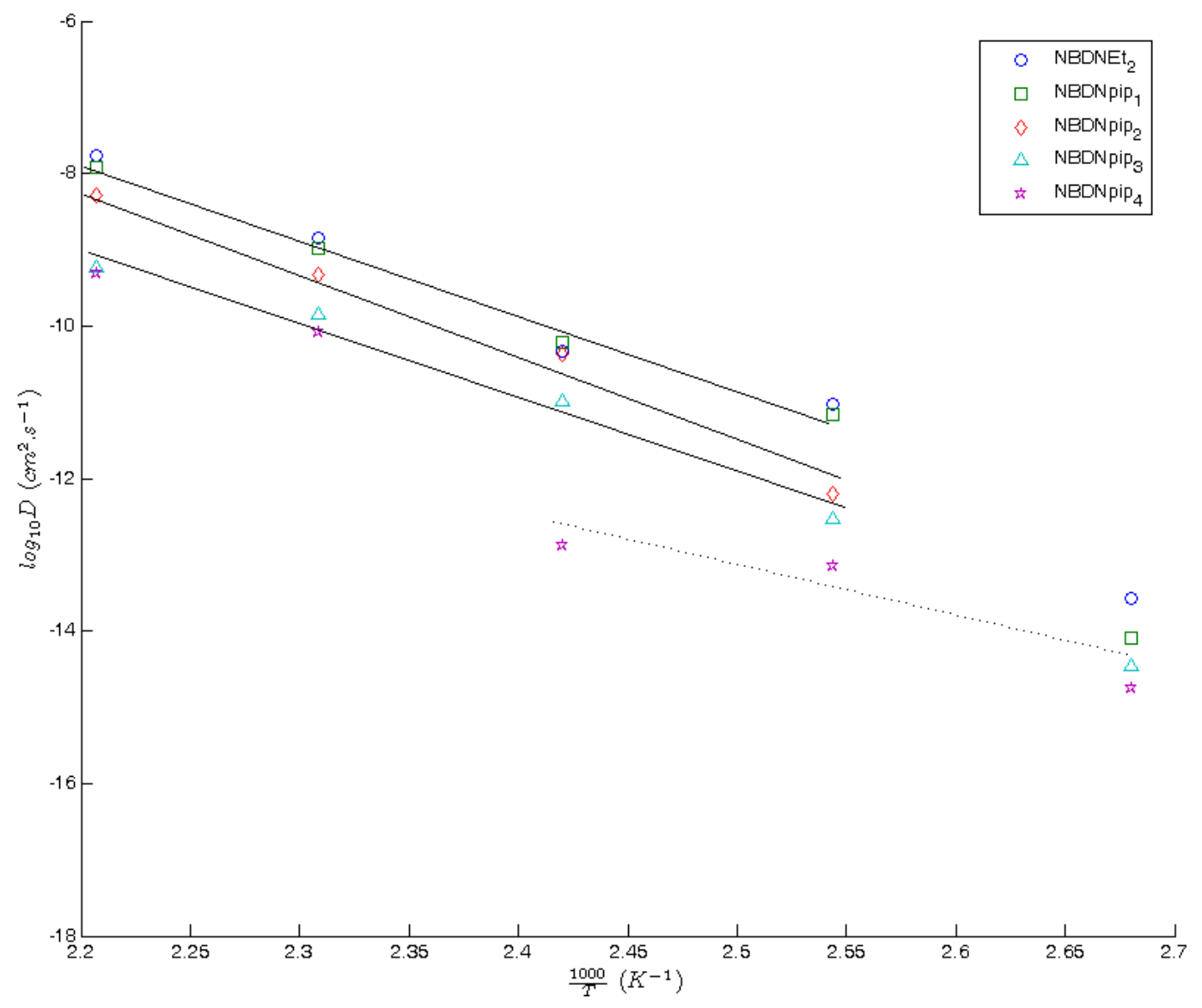

Figure 6. Arrhenius plot of amorphous polystyrene (PS2M) diffusion coefficients. Probes legend is given in table 2.

Lines are drawn only as guides. The dotted line (Npip4), however, has a lower slope than other 4 5 6 7 8 9 

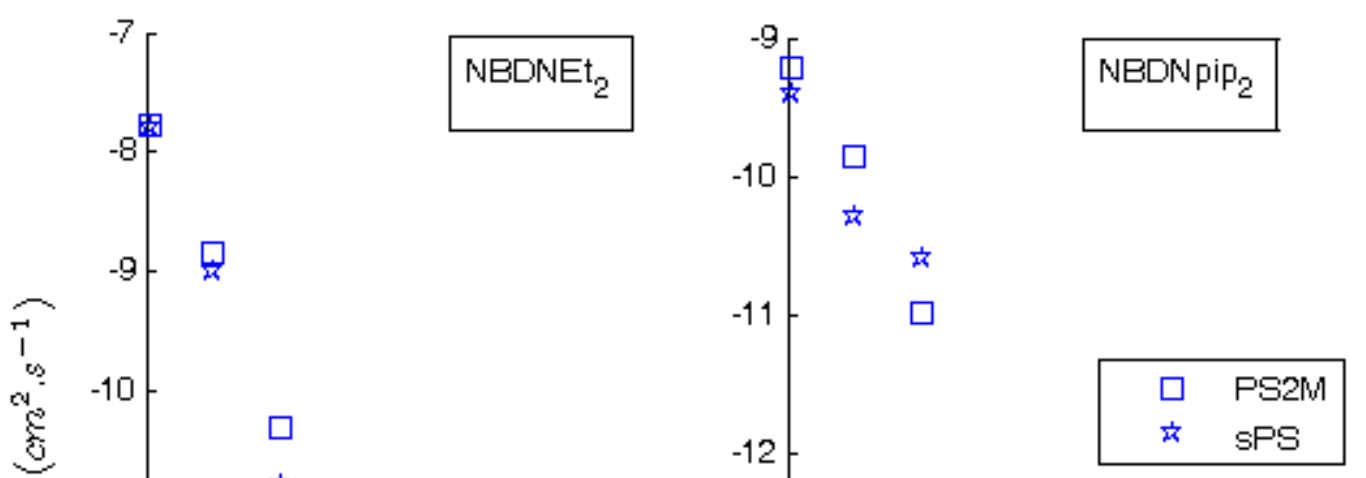

Figure 7. Comparison of the diffusion of two probes in amorphous (PS2M) or semi crystalline polystyrenes (sPS). Probes structures are given in table 2. 


\section{$1 \quad$ List of abbreviations}

$2 \quad \mathrm{M}_{\mathrm{W}} \quad$ Molecular weight

3 D diffusion coefficient (

4 Ea Activation energy

5 FRAP Fluorescence recovery after photo bleaching

$6 \quad$ A'P tabulated polymer parameters (from the Piringer diffusion model)

$7 \quad \mathrm{C}$ tabulated polymer parameters (from the Piringer diffusion model)

8 T temperature

9 D* overestimated diffusion coefficient (obtained from the Piringer model)

10 D'0 diffusion coefficient at infinite temperature (from the Limm model)

$11 \alpha$ tabulated polymer parameters (from the Limm model)

12 K tabulated polymer parameters (from the Limm model)

13 PVC, polyvinylchloride

14 PA polyamide

15 RH relative humidity

16 PET polyethylene terephtalate

17 PS2M Polystyrene with High molecular weight (amorphous PS)

18 sPS syndiotactique polystyrene (semi-crystalline)

19 ROI region of interest

20 NBD : NBD is the fluorescent kernel of the probes (nitrobenzoxadiazol) 